\title{
COMPARATIVE ANALYSIS OF TRIAL VAGINAL HYSTERECTOMY AND ABDOMINAL HYSTERECTOMY
}

\author{
Nidhi Sharma ${ }^{1}$
}

${ }^{1}$ Associate Professor, Department of Obstetrics and Gynaecology, Saveetha Medical College, Chennai, Tamilnadu.

ABSTRACT

\section{AIMS}

The indications of hysterectomy are varied and uterus can be removed using any of the abdominal, vaginal or laparoscopic approach. Although, comparative trials have been done before the exact indications and intraoperative technique is still a matter of debate. If hysterectomy is indicated, most important decision is which way surgery should be performed. Hence, this study was planned to compare non-descent vaginal hysterectomy with abdominal hysterectomy in terms of indications and complications.

\section{DESIGN}

Prospective case control study.

\section{SETTING}

Department of Gynecology, Saveetha Medical College and Hospital, Saveetha University, Jan 2013 to March 2015.

\section{PARTICIPANTS}

Ninety cases of non-descent vaginal hysterectomy (Mean age 38.8 and parity 3.99) done for varied indications of hysterectomy; 90 cases of total abdominal hysterectomy were taken as controls.

\section{MAIN OUTCOME MEASURES}

The primary outcome was assessed as the amount of blood loss, conversion to laparotomy, average duration of catheterization, duration of hospital stay, duration of immobilization after surgery. Secondary outcome was time taken for surgery, occurrence of operative site infection and need for blood transfusion.

\section{RESULTS}

The average blood loss in NDVH cases is $392.77 \mathrm{cc}$ as compared to TAH controls 595cc. Average time taken for NDVH cases is 53.8 minutes. TAH controls were completed in an average of 69.4 minutes. Two patients with previous LSCS were converted to open laparotomy; $74.4 \%$ of patients in our study had catheterization for less than $20 \mathrm{hrs}$.; $75.5 \%$ of patients were ambulatory on first postoperative day. There were no injuries to bowel, bladder and ureter or fistula formation in our series of TAH and NDVH cases. Abdominal wound infection occurred in $13.33 \%$ of TAH cases while vault infection was encountered in 3.33\% of NDVH patients [z value 2.427; $\mathrm{p}<0.05$ (Significant)]. Four patients in TAH group had unexplained fever [z value 2.0231; $\mathrm{p}<0.05$ (Significant)].

\section{CONCLUSION}

Previous LSCS increases conversion rate to laparotomy. NDVH carries a total blood loss less than TAH. There is fewer incidences of postop febrile morbidity and operative site infection.

\section{KEYWORDS}

Trial Hysterectomy, Hysterectomy, Nondescent, Vaginal.

HOW TO CITE THIS ARTICLE: Nidhi Sharma. "Comparative Analysis of Trial Vaginal Hysterectomy and Abdominal Hysterectomy." Journal of Evolution of Medical and Dental Sciences 2015; Vol. 4, Issue 95, November 26; Page: 16052-16056, DOI: $10.14260 /$ jemds/2015/2344.

\section{INTRODUCTION}

The indications of hysterectomy are varied and uterus can be removed using any of the abdominal, vaginal or laparoscopic approach.

Financial or Other, Competing Interest: None.

Submission 28-09-2015, Peer Review 29-09-2015,

Acceptance 16-11-2015, Published 25-11-2015.

Corresponding Author:

Dr. Nidhi Sharma.

No. 5, Jayanthi Street,

Dr. Seethapathi Nagar,

Velacherry, Chennai-600042,

Tamilnadu, India.

E-mail: drbonuramkumar@yahoo.co.in

DOI:10.14260/jemds/2015/2344.
Although comparative trials have been done before the exact indications and intraoperative technique is still a matter of debate. If hysterectomy is indicated, most important decision is which way surgery should be performed.

\section{Advantages of Abdominal Hysterectomy:}

1. Lesser surgical skill is required.

2. Cases where oopherectomy is indicated.

3. Uterine enlargement $>500 \mathrm{gms}$.

4. Suspected pathology in adnexal organs, e.g., benign and malignant ovarian neoplasms, tubo-ovarian inflammatory cyst, endometriosis of ovary/uterosacral ligaments. 
Advantages of Vaginal Hysterectomy over Abdominal Hysterectomy:

1. Intraoperative:

a. Avoiding an abdominal incision reduces depth and length of aneasthesia and hence its complication.

b. Extreme obesity, although complicates both abdominal and vaginal routes, but technical difficulties are less with vaginal hysterectomy.

c. Repair of vaginal wall defects is easier with vaginal hysterectomy.

d. Correction of an undiagnosed enterocele is easily done vaginally.

\section{Postoperative:}

a. Vaginal hysterectomy is almost an extraperitoneal operation, so the chances of postoperative ileus is reduced.

b. All morbidity associated with an abdominal incision (i.e. discomfort, infection, dehiscence, incisional hernia are avoided).

c. Early ambulation leads to decreased nursing care requirement.

d. Early return of bowel function leads to decreased parenteral fluid requirement.

e. Decreased postoperative infectious morbidity leads to decreased antibiotic requirement.

f. Faster recovery leads to early discharge from hospital.

g. Vaginal hysterectomy is better tolerated by elderly patients and those with complicated medical diseases.

\section{Remote:}

a. Patient satisfaction is good for not having an abdominal scar.

b. Less amount of postoperative adhesions and hence less subsequent complications.

\section{Disadvantages of Vaginal Hysterectomy over Abdominal Hysterectomy:}

1. Inadequate exposure of pelvic pathology due to acute or chronic infections, adhesions or endometriosis.

2. Need of concurrent evaluation or treatment beyond the field of exposure is not fulfilled as in cases of adnexal masses, diffuse endometriosis and chronic pelvic pain.

These disadvantages can be overcome by using laparoscopic assistance. The intra-abdominal pathology and adhesions can be accessed via a subumbilical port. Adhesiololysis and tubo-ovarian dissection if warranted can be carried out by employing additional iliac fossa ports.

\section{MATERIALS AND METHODS}

This prospective study was done in our teaching institute from Jan. 26, 2013 to March 31, 2015, after Institutional Review Board Approval. The commonest age group in our study is 36 to 40 years NDVH and also for TAH. One eighty six (186) patients were analyzed. Ninety were operated by non-descent vaginal hysterectomy. Ninety cases of abdominal hysterectomy served as controls.
Median age of NDVH and TAH patients is 36 to 40 years. The groups were comparable with respect to age and parity. Majority of groups were multiparous. Mean parity of NDVH was 3.99. Mean parity of TAH was 3.55. The symptom profile of TAH and NDVH was also comparable. The sizes of uterus in NDVH cases were normal to 6 weeks and TAH had the uterine size between 12 to 14 weeks. For enlarged uterus vaginal hysterectomy were performed with the use of volume reduction techniques:

1. Bisecting the uterus in two halves to avoid tension on the pedicles, avoid slipping of pedicles.

2. Cervical amputation for greater access.

3. Wedge coring of uterine anterior and posterior walls with amputation of cervix.

Maximum number (43.33\%) of patients in our study had normal-sized uteri, the largest uterus delivered vaginally in our study size was $12 \mathrm{~cm}$. In $5.55 \%$ of patients, a diagnosis of adenomyosis was made. In $25.55 \%$ of patients, a diagnosis of DUB was made by exclusion. The patients with dysmenorrhoea, heavy prolonged menstrual blood flow and enlarged tender uteri experienced a dramatic relief from hysterectomy.

An $8.98 \%$ of patients in our study had premalignant lesions of uterus or cervix. One of the 3 diabetics operated by NDVH had post-operative urinary tract infection, although all diabetics were controlled well by insulin. None of the patients in non-diabetic group had urinary infection, although they had postoperative vault infection which was treated with broadspectrum oral antibiotics for 5 days.

Prior caesarean section is not a contraindication, but does require a more experienced surgeon if vaginal route is opted (Shaw's textbook of operative gynecology $6^{\text {th }}$ edition 2001). In two patients with earlier lower segment caesarean section scar, NDVH had to be converted to open laparotomy due to uncontrolled intraoperative hemorrhage. In one patient with previous caesarean section, hysterectomy was done vaginally without any complications.

The most frequent cause of laparotomy was adhesions followed by non-descent of uterus. This is in accordance with our study, where previous LSCS led to adhesions and difficulty in achieving planes of dissection and laparotomy conversion of NDVH planned cases. The decision to convert a vaginal hysterectomy into an abdominal procedure was prompt because delay means an increased blood loss and a greater need for blood transfusions.

The variables assessed preoperatively were age, indications, parity and diabetic status. The variables assessed intraoperatively was fall in haematocrit and duration of hysterectomy. The need for conversion to laparotomy in cases of nondescent vaginal hysterectomy was assessed. Postoperative variables that were analyzed were duration of catheterization and hospital stay in days.

The statistical analysis was performed using students ' $\mathrm{t}$ ' test. The confidence interval being 95\%. The statistical significance was defined as $\mathrm{p}<0.05$.

\section{DISCUSSION}

In our study, 27 patients, $30 \%$ of NDVH were done for symptomatic fibroids. 
This is in accordance with Te Linde's operative gynaecology, 9th edition, 2003 which states that myomas account for $30 \%$ of hysterectomies when they are associated with discomfort, urinary frequency or obstruction, menorrhagia or if they significantly increase in size.(1) None of the patients in our series of 27 benign fibroids had leiomyosarcoma.

Preoperative sonographic estimation of uterine volume is an aid to determine the route of hysterectomy.(2) For large uterus volume reduction techniques were used.(3,4) Prior caesarean section is not a contraindication, but does require a more experienced surgeon if vaginal route is opted (Shaw's textbook of operative gynecology 6th edition 2001).

In two patients with earlier lower segment caesarean section scar, NDVH had to be converted to open laparotomy due to uncontrolled intraoperative hemorrhage. One patient with previous caesarean section was hysterectomized vaginally without any complications. In a retrospective study done by M. Furuhashi and N. Saganuma.(5) A 1736 vaginal hysterectomies were studied at Handa City Hospital from 1990-1999 with special reference to those cases ending in laparotomy. The most frequent cause of laparotomy was adhesions followed by non-descent of uterus. This is in accordance with our study where previous LSCS led to adhesions and difficulty in achieving planes of dissection and laparotomy conversion of NDVH planned cases.

\section{Uterivaginal Descent and NDVH}

Uterovaginal descent makes the surgery easy, but does not predict the success of vaginal surgery. Both patients who required laparotomy had first degree uterivaginal descent. Three patients with first degree uterivaginal descent had intraoperative hemorrhage of which one was controlled vaginally and two required laparotomy for the control of bleeding. None of the patients with no uterine descent had to be converted to open laparotomy suggesting thereby that the presence or absence of descent does not alter the success rates of NDVH. In no descent group, none of the patient had intraoperative hemorrhage.

\section{An Objective Assessment of Mobility}

No patient with good uterine mobility required laparotomy or had any post-operative complications. Two patients with restricted mobility were converted to open laparotomy due to uncontrolled bleeding. A confounding factor was previous LSCS, which affected the mobility of uterus on clinical examination and laparotomy rates. Mobility is a better case selection criterion than descent.

\section{Pre-operative Preparation}

Prophylactic antibiotic was given $1 \mathrm{hr}$. prior to surgery in our group of patients, so that the antibiotic levels peak at the time of surgery. Randomized controlled trials have shown a significant reduction in febrile morbidity and infection in both abdominal and vaginal hysterectomy with the use of perioperative antibiotics.

\section{Intraoperative Analysis}

Average blood loss calculated by fall in haematocrit was calculated. Transfusion rates were measured. The average blood loss in our series of NDVH cases is $392 ; 77 \mathrm{cc}$ as compared to TAH controls 500cc. Maximum number of NDVH patients had blood loss ranging from $300-400 \mathrm{ml} ; 83.32 \%$ had blood loss $<500 \mathrm{ml} ; 16.66 \%$ had blood loss $>500 \mathrm{ml}$. Only one patient had blood loss $>700 \mathrm{ml}$. In our study, the average time for NDVH cases is $53.8 \mathrm{~min}$. TAH controls were completed in an average of 69.4 minutes.

\section{Post-operative Care}

After vaginal hysterectomy, patients were given a regular diet as soon as post-anaesthesia nausea resolves. Patients were also able to tolerate solid food on first post-operative day following abdominal hysterectomy.

\section{Duration of Catheterization}

Prolonged postoperative catheterization was avoided in most patients with the help of good enthusiastic anesthesiologists and nursing staff.(6) Foley's catheter for bladder drainage overnight following hysterectomy; $74.44 \%$ of patients in our study had catheter removed in less than $20 \mathrm{hrs}$. In $23.33 \%$ of patients, the catheter was removed on postop day 2. Only 2 patients in our study required catheterization for more than 2 days.

\section{Length of Post-operative Hospitalization}

In our study, $80 \%$ of patients were discharged on postoperative day 5 because inpatient stay is free and there is no pressure for bed and majority of the patients feel comfortable staying indoors even if they are fit for discharge. Some centers discharge patients in less than 24 hours in developed countries, where the health care cost is borne by the government.(7) One patient was discharged on post-operative day 3. Four patients were discharged on postoperative day 4 .

\section{COMPLICATIONS}

Mortality from hysterectomy in most medical centers is 1-2/1000. In our study, we have attempted to do non-descent vaginal hysterectomy with proper use of blood transfusion and antibiotics and intraoperative techniques and analyzed the result in terms of indications and successful outcome. Three patients of NDVH had vault bleeding intraoperatively. Two were converted to open laparotomy to control bleeding and in one patient we were able to control bleeding vaginally; $10 \%$ of TAH patients required blood transfusion.

A $7.77 \%$ of NDVH cases required blood transfusion. $\mathrm{Z}$ value $=0.524$ (Non-significant). Four patients in TAH group had unexplained fever, while no patient in NDVH group had this complication [ $\mathrm{z}$ value $=2.0231 ; \mathrm{p}<0.05$ (Significant)]. Four patient in TAH and one patient in NDVH group developed urinary tract infection [z value $=1.361$ (Non-significant)] Complications can occur in as many as $25 \%$ of patients undergoing abdominal hysterectomy. Complications in our series is depicted as a comparison to earlier series in table 3. $(8,9)$

There were no injuries to bowel, bladder, ureter or fistula formation in our series of TAH and NDVH cases. Abdominal wound infection occurred in 12 (13.33\%) of TAH cases, while vaginal vault infection was encountered in only 3 $(3.33 \%)$ of NDVH cases [ $\mathrm{z}$ value $=2.427 ; \mathrm{p}<0.05$ (Significant)] A total complication rate of NDVH in our study is $14.44 \%$ as compared to total abdominal hysterectomy which is $31.21 \%$. 


\section{CONCLUSION}

Our study suggests that Trial Vaginal Hysterectomy carries a total complication rate less than Abdominal Hysterectomy when proper patient selection, intraoperative techniques and post-operative care is provided. There are fewer incidences of post-operative febrile morbidity and operative site infection.

\section{REFERENCES}

1. Gambone JC, Lench JB et al. Validation of hysterectomy indication and the quality assurance process. Journal of Obstet Gynaecol 1989;75:1045.

2. Shirish S. Sheth, Nilesh M. Shah. Preoperative sonographic estimation of uterine volume: An aid to determine the route of hysterectomy. Journal of gynaecol Surgery 2002;18:13-22.

3. Luigi Benassi et al. Vaginal hysterectomy valid for fibroid management, even for enlarged uteri. American Journal of obstet gynaecol 2002;157:1561-65.

\begin{tabular}{|c|c|c|}
\hline Indication & $\begin{array}{c}\text { No of } \\
\text { Patients }\end{array}$ & $\mathbf{\%}$ \\
\hline Fibroid & 27 & 30 \\
\hline $\begin{array}{c}\text { Chronic cervicitis not } \\
\text { responding to treatment }\end{array}$ & 27 & 30 \\
\hline Adenomyosis & 5 & 5.55 \\
\hline $\begin{array}{c}\text { Dysfunctional } \\
\text { uterine bleeding }\end{array}$ & 23 & 25.55 \\
\hline $\begin{array}{c}\text { Premalignant lesion of } \\
\text { cervix } \\
\text { /endometrium/endocervix }\end{array}$ & 8 & 8.98 \\
\hline Total & $\mathbf{9 0}$ & $\mathbf{1 0 0}$ \\
\hline $\begin{array}{c}\text { Table 1a: Distribution of Nondescent Vaginal } \\
\text { Hysterectomy Cases According to Diagnosis }\end{array}$ \\
\hline
\end{tabular}

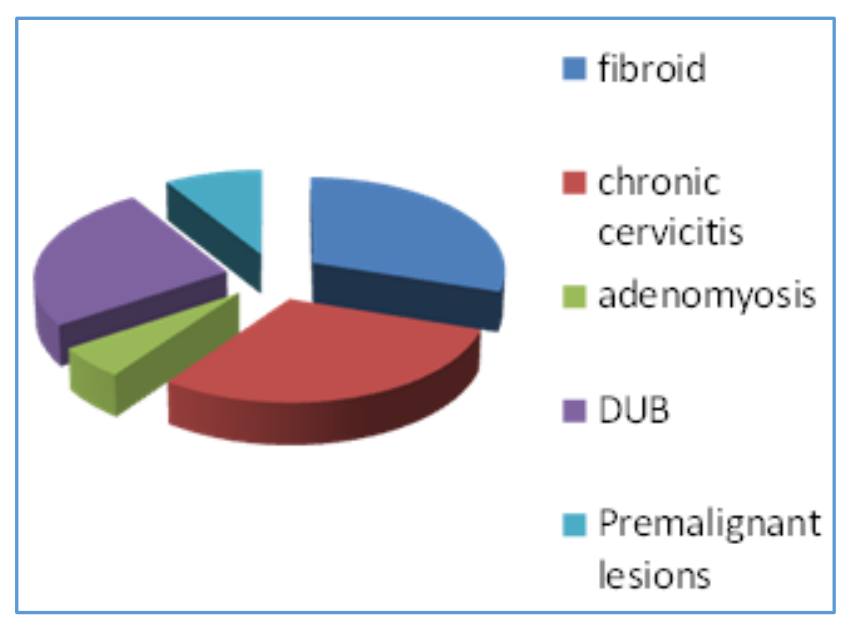

Table 1b: Distribution of Nondescent Vaginal Hysterectomy Cases According to Diagnosis
4. Pratt G H. Vaginal hysterectomy by morcellation. Mayo Clinic Proc 1978;43:374.

5. Furuhashi M, Suganuma V. Surgery of vaginal hysterectomy ending in laparotomy. Arch Gynaecol Obstet 2002;267:57-58.

6. Richardson AC, Lyon JB, Graham EE. Abdominal hystrectomy: relationship between morbidity and surgical technique. American Journal of Obstet Gynaecol 1973:115:514.

7. Stoval T, Summitt R, Bran D et al. Outpatient vaginal hysterectomy: a pilot study 1992;80:145.

8. Garry R. Comparison of hysterectomy techniques and cost benefit analysis. Clin Obstet Gynaecol. 1997;11(1):137148.

9. Harris W. Early complications of abdominal and vaginal hysterectomy. Obstet Gynaecol Suev 1995;50:795.

\begin{tabular}{|c|c|c|}
\hline Indication & $\begin{array}{c}\text { No of } \\
\text { Patients }\end{array}$ & $\mathbf{\%}$ \\
\hline Fibroid & 18 & 20 \\
\hline $\begin{array}{c}\text { Chronic cervicitis not responding } \\
\text { to treatment }\end{array}$ & 20 & 22.22 \\
\hline Adenomyosis & 5 & 5.55 \\
\hline DUB & 18 & 20 \\
\hline $\begin{array}{c}\text { Premalignant lesions of } \\
\text { cervix/endometrium/endocervix }\end{array}$ & 9 & 10 \\
\hline Tubo-ovarian abcess with PID & 9 & 10 \\
\hline Dermoid ovarian cyst & 5 & 5.55 \\
\hline Endometriosis & 6 & 6.66 \\
\hline Table 2a: Distribution of Abdominal Hysterectomy \\
Cases According to Diagnosis
\end{tabular}

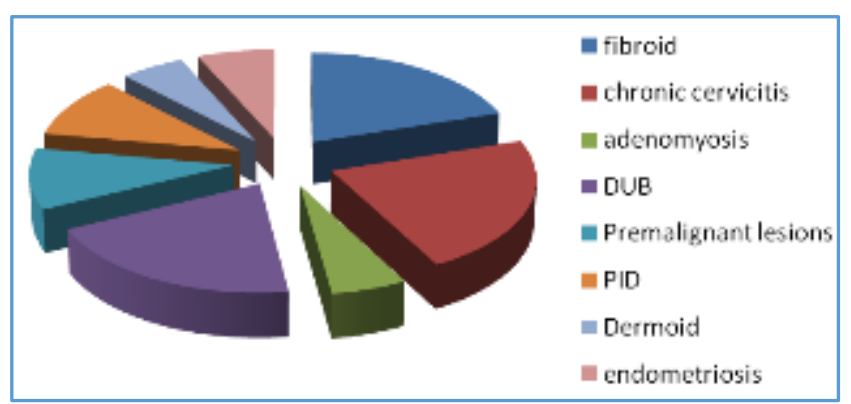

Table 2b: Distribution of Abdominal Hysterectomy Cases According to Diagnosis 


\begin{tabular}{|c|c|c|c|c|c|c|}
\hline & \multicolumn{2}{|c|}{$\begin{array}{c}\text { Gary and Dicker } \\
\text { et al. (1997) }\end{array}$} & \multicolumn{2}{c|}{ Harris WJ (1995) } & \multicolumn{2}{c|}{ Present Study } \\
\hline & TAH & NDVH & TAH & NDVH & TAH & NDVH \\
\hline No. of patients & 1283 & 568 & 1184 & 530 & 90 & 90 \\
\hline Transfusions & $15.4 \%$ & $8.3 \%$ & $2-12 \%$ & $2-8.3 \%$ & $10 \%$ & $7.77 \%$ \\
\hline \multicolumn{7}{|c|}{ Infection } \\
\hline Unexplained fever & $16.8 \%$ & $7.2 \%$ & $10-20 \%$ & $0.5-8 \%$ & $4.44 \%$ & 0 \\
\hline Operative site infection & $8.1 \%$ & $2.1 \%$ & $6.6-24.7 \%$ & $3.9-10 \%$ & $13.33 \%$ & $3.3 \%$ \\
\hline Pelvic & $1.3 \%$ & $1.2 \%$ & $3.2-10 \%$ & $3.9-10 \%$ & 0 & 0 \\
\hline Urinary tract & $7 \%$ & $3.4 \%$ & $1.1-5 \%$ & $1.7-5 \%$ & $4.44 \%$ & $1.11 \%$ \\
\hline Pnuemonia & $0.4 \%$ & $0.4 \%$ & $0.4-2.6 \%$ & $0.29-2 \%$ & 0 & 0 \\
\hline \multicolumn{7}{|c|}{ Injuries } \\
\hline Bladder & $0.3 \%$ & $1.6 \%$ & $1-2 \%$ & $0.5-1.5 \%$ & 0 & 0 \\
\hline Bowel & $0.3 \%$ & $0.6 \%$ & $0.1-1 \%$ & $0.1-0.8 \%$ & 0 & 0 \\
\hline Ureter & $0.2 \%$ & 0 & $0.1-0.5 \%$ & $0.05-0.1 \%$ & 0 & 0 \\
\hline VVF & \multicolumn{7}{|c|}{$0.1-0.2 \%$} & $0.1-0.2 \%$ & 0 & 0 \\
\hline \multicolumn{7}{|c|}{ Table 3: Complication Rates of Nondescent Vaginal Hysterectomy as } \\
\hline
\end{tabular}

